TALLER DE HISTORIOGRAFÍA:

Ensayos 



\title{
Elliott in the Making, 1943-1963. Or: an Etonian Moment?
}

\author{
Julio A. PARDos* \\ Universidad Autónoma de Madrid
}

«It is easier to describe a stile

than to isolate and examine

a specific work in it»

(John G. A. Pocock, 1970).

Para Saúl,

de quien aprendí compartiendo taller — el aula, los textos.

(i)

The Revolt of the Catalans fecha su prefacio en junio de 1962. En el texto, publicado en 1963, encuentra acomodo la información, a estas alturas ciertamente ingente, acumulada en una década de búsquedas, planteada en 1952/53, visible desde 1955, fundamentada en dos estancias casi de un año cada una en depósitos archivísticos españoles. El acomodo de esa información se hace mediante una articulación formal que merece algún comentario si, como es el caso, de detectar un estilo se trata. Intentemos localizar esos marcadores formales, empezando por la dispositio del texto. Preside su arquitectura, explícitamente, el reconocimiento de la diversidad territorial que viene resultando ser el motor de la encuesta: capítulos inicial y terminal, sobre «Castilla y Aragón», y sobre "Cataluña y Portugal», respectivamente. Conectándolos, una combinación de narrativa y análisis que sin duda es uno de los logros mayores del texto. Gozne de esa combinación, sin duda, el capítulo 7, "Olivares y el futuro de España», donde además de apuntarse que los impulsos de lo que fuera investigación inicial se mantienen, se deja claro que se está atendiendo el "Spain» indicado en el subtítulo - A Study in the Decline of Spain, 1598-1642-. Las nociones de "constitutional pattern", y de "administrative development " se movilizan constantemente, discretamente. Y lo hacen al compás de la atención al despliegue del entramado de cargos y oficios que sirve al gobierno de la «Monarquía». Preparando el capítulo dicho, el 7, el final del anterior, el 6, trae en un par de páginas el leit motiv de éstas y de muchas páginas que vendrán, en este texto y en otros venideros: el caso es de «failure of comprehen-

" Proyecto de Investigación (HAR2011-27562). 
sion», la falta de comprensión mutua, así «the root of the difficulties», que se agravan cuando el predicament es «the almost superhuman task of governing and holding together an empire of innumerable provinces", problema de la supervivencia de un imperio de esa composición «in a warring world». En la narrativa de la revolt propiamente dicha prácticamente no se entra con The Revolt. La encuesta era otra. En lugar de eso, el broche epilogal subraya cómo «as a result of 1640, the Catalans were becoming aware of Spain. Aware of Spain as a political community», y cómo, resultado de esa crise de conscience catalana, «the Principality was slowly beginning to emerge from the isolation in which it had been buried - partly through its own fault, partly through the fault of the Court». Un caso ejemplar de «tragic irony». El lector abandona el texto con esta impresión también en la retina: «The revolt of the Catalans at once epitomized and foreshadowed the tragedy of Spain». Una tragedia española: es el último sintagma del último par de líneas. Que se trataba de «a tragedy», venía muy al principio, ya en la página ocho, en el punto crucial- y cabe apuntar que la atención americana será la primera tarea que encare John Elliott inmediatamente tras la aparición de The Revolt- que se hacía cargo de una decisión crucial: «...reserving America to Castile...».

Para confirmar que The Revolt of the Catalans no promete y trae únicamente historia de la revuelta de los catalanes, en menos de un año, en marzo de 1963más o menos cuando The Revolt se comunica en forma impresa- Elliott cierra otro texto. Es Imperial Spain, 1469-1716, que, aquí y ahora, puede leerse adecuadamente como para-texto del texto de The Revolt. Es posterior y es anterior a la investigación mayor. Procede, como se sabe, de las lecciones impartidas por un joven profesor de 27 años recién nombrado assistant lecturer en la Universidad. Arrancaron, como lecciones, de ese año de 1957, y amplificando el generalista capítulo 1 de The Revolt, llevan su asunto, el de la diversidad territorial y el «engaño» y «desengaño» imperial, al cierre formal de 1716. Literalmente, un Spain in the making, puesto que «the creation of Spain» en su punto de inicio le sirve para plantear un «overarching theme», «the rise and decline of Spanish power», también organizado sabiendo que «the Age of Olivares» constituye en eso «the critical turning point». La atención al «constitutional pattern», al working of the constitution, vertebra el relato, perfectamente informado por lo demás en cuanto a historia social y económica. El título podía tener lecturas equívocas, en la España de principios de los sesenta. En su interior operaba una inteligente prolongación matizada del paradigma constitucional, un inteligente filtrado de eso por el monopolio castellano del botín de cargos, y una exquisita, si breve, atención a la envoltura cultural de todo ello, con algunos puñados de líneas sobre la cultura literaria del momento sencillamente de antología. También en la dispositio del texto Elliott se ha permitido deslizar claves de lectura muy indicativas. El libro se abre con un párrafo memorable en el más puro estilo de Joaquín Costa: « $A$ dry, barren impoverished land: a 10 per cent of his soil bare rock; 35 per cent poor and improductive; 45 per cent moderately fertile; 10 per cent rich... No natural centre, no easy routes. Fragmented, disparate... ». Y se cierra con un guiño emblemático, una cita de Ortega: «...an epitaph... "Castile has made Spain, and Castile has destroyed it"». Pero no se 
conectan, el espíritu de Costa, la sentencia de Ortega, con lo previsible, sino con un imprevisto ejercicio de madurez historiográfica cualquier cosa menos esencialista, con un desenvolvimiento argumental sostenido- en torno al contrapunto Castilla-Cataluña en el hacer y deshacerse de España- que alejan el texto del genero aparente al que pertenece, el libro de texto universitario. O quizás lo acercan a lo que debiera ser su esencia misma. No es receptáculo de información, y aunque viene de lecciones universitarias y puede ser utilizado con mucho provecho en la docencia universitaria, la información se organiza en torno a un argumento, y siempre se sirve en un eficaz ejercicio de prosa expositiva. En 1963 su presentación afirmaba que se trataba de apuntar hacia asuntos que parecían de importancia. En 2001 el autor, al presentar de nuevo el reprint de un texto que permanecía incambiado, es más generoso, para empezar consigo mismo, y nos brinda una pista: sí, "the aim of the book was always to identify important issues", pero ahora se dice que también «to suggest ways of looking to them». Formas de mirar. Formas de atención de la mirada hacia lo ya sabido, quizás mal sabido por consabido.

Con ocasión de una sentida nota necrológica en las páginas de la catalana Serra d'Or, en 1960, que ampliaba la publicada en el Times en la semana siguiente al fallecimiento del historiador catalán, John Elliott se permitía un interesante apunte de historia comparada, de historia comparada de la historiografía, al asimilar la posición de Vicens a la de un Namier, y la del medio cuya gelidez esa iconoclastia rompía, a la de algo comparable a una whig interpretation. Se trasladaban a la historiografía española categorías y avatares que pertenecían al medio en que John Elliott había precisamente conformado su personal «way of looking», su personal forma de mirar. Quizás un de te fabula narratur puede apuntarse aquí. Como esa mirada es ingrediente esencial de The Revolt, y de Imperial Spain, y del engarzarse otros textos al compás de casi una década, conviene quizás prestarle alguna atención, y descender, no a cuestiones de información documental, o tratamiento de método y técnicas, sino a estratos más profundos, pero en absoluto arcanos, de «propia personalidad y experiencia», los decisivos en el taller del historiador, según el mismo Elliott apuntara en 1972, precisamente en páginas de la muy orteguiana Revista de Occidente. Esto supone retroceder, previsiblemente, hacia fechas de los alrededores de 1930.

\section{(ii)}

Durante el año académico de 1926-1927, y en calidad de «Deputy for the Regius Professor of Modern History", Joseph Robson Tanner impartió una serie de lecciones en la Universidad de Cambridge. Se publicarían inmediatamente, como English constitutional conflicts of the Seventeenth Century, 1603-1689, en 1928, reimpresas cuatro veces hasta 1952. Y el mapa es el siguiente: historia constitucional, del siglo XVII como encrucijada crítica; acuñación de esa historia constitucional reconociéndose avatar penúltimo de una cadena cuyos eslabones anteriores 
se nombran: S. R. Gardiner, C. H. Firth; mosaico territorial— Inglaterra y Escociay la forma de su unión, como paisaje y problema. E indicación del talante drámático del asunto que no puede dejar de asumir el relato: un episodio de «revolucion» puede y debe ser tratado como episodio de un «historical drama, and this conception can be nowhere fruitfully aplied than to the history of the seventeenth century... the piece is on the stage for nearly a hundred years. The first Act ends with an execution...». Es todo un paradigma, expuesto muy sintomáticamente por uno de sus practicantes menores, pero precisamente quizás por ello muy eficazmente. Y la identificación y encausamiento de ese paradigma, también su retención, transformación y supervivencia, es la tarea que conforma la historiografía británica en los años inmediatamente subsiguientes, años treinta y cuarenta que también incluyen la catástrofe de una segunda Guerra Mundial.

En 1931 Herbert Butterfield publicaría The Whig interpretation of History. Los dos años precedentes había visto la aparición de un par de monografías por un entonces desconocido historiador de origen polaco, Lewis Namier, The structure of politics at the accesión of George III (1929), seguida de England in the Age of the American Revolution (1930). Identificación, encausamiento, alternativa paradigmática, todo ello estaba servido en ese paso a los años treinta donde, quizás y con todo, más llamativo resultara la publicación en 1930 de una pieza más festiva: 1066 and All That, de W. C. Sellar y R. J. Yeatman, de expresivo subtítulo, A Memorable History of England, comprising all the parts you can remember, including 103 Good Things, $5 \mathrm{Bad}$, and 2 Genuine Dates, donde el encausamiento ahora se enderezaba hacia el conservadurismo del entramado educativo primario y secundario en Inglaterra.

En 1930, si del contrapunto español se trata, el clima lo marca no obra festiva alguna, sino un happening de mucho empaque y resonancia, el homenaje que intelectuales catalanes brindaban a intelectuales castellanos que salieran al paso de una agresión lingüística perpetrada por una Dictadura - un episodio que acaba de reconstruir micrográficamente Xavier Pericay. Y al año siguiente, en el escenario de unas Cortes Constituyentes españolas, Claudio Sánchez-Albornoz impartía lecciones de historia de España agitando victimismo castellanista, para empezar, en presencia del mismísimo Ortega y Gasset- ya se sabe: de la provocación del "Castilla ha deshecho a España», al reproche del «España ha deshecho a Castilla». Un historiador catalán, Ferrán Soldevila, acababa de enzarzarse con Ramón Menéndez Pidal con ocasión de la publicación de La España del Cid (1929) y pasaba luego a convertir sus posiciones en una importante Història de Catalunya (1934/35). Todavía no toca dar entrada a un jovencísimo historiador gironés en ciernes que, en ese momento, ya apuntando maneras, complementaría una investigación sobre la Barcelona - y la Cataluña- de Fernando el Católico con artículos de polémica respondona con el mismo Soldevila.

Son escenarios que se mantuvieron, claro está, separados, el que encausaba - a la vez que prolongaba - el constitucionalismo del paradigma whig y el que hacía del encuentro-desencuentro castellano-catalán leit motiv del momento constituyente español. John Elliott nació en Reading el 23 de junio de 1930, y el 
acontecimiento pasó razonablemente desapercibido para los más entre tanto ruido. Pero con los episodios aludidos, unos pocos pero sintomáticos, no del todo arbitrariamente elegidos, al convertirse en cultura, institucionalización y atmósfera, señalan el clima en que pudo formarse la mirada del historiador, con su personalidad, con su experiencia. Son hilos sueltos, pero significativos que apuntan algunas de las posibilidades del tejido, años cuarenta, en que se arropa la formación de la mirada, the way of looking, que Elliott nos decía que quizás era lo decisivo del despliegue de textos de 1963. Son fibras ajenas. El tejido de algunas de ellas terminará siendo propio del historiador. Personal e impersonal a la vez.

El punto en que puede empezar a rastrearse el hacerse tejido de esas fibras tiene fecha. Es el año 1943. El año de la entrada de John Elliott en Eton. Y allí, primero, lenguas clásicas. Muy pronto, lenguas modernas, vale decir, francés y alemán. Con esto, y hasta 1948, inmersión por tanto en un medio- y en años cruciales para la formación de la personalidad y la transformación propia de la experiencia - donde se está jugando la identidad misma de lo que se llama literatura europea. El sintagma esconde una tremenda complejidad, entre otras cosas porque de esa literatura europea depende la posibilidad misma de una literatura universal. Es de lo que quería hablar el filólogo alemán Victor Klemperer en un texto muy elocuente de 1929, Weltliteratur und europäische Literatur, literatura universal y literatura europea: de la centralidad, y del problema, de ese complejo franco-alemán. De la periferización entonces de otras literaturas, como la inglesa o la hispana áureosecular o luego de plata. La primera, después de haber servido para romper la preponderance francesa, había visto como se le escapaba la hegemonía en una aetas goethiana. La segunda, peor: nunca había acabado de transferir como europeas las peculiaridades de su Siglo de Oro. En los cuarenta, esa nuclearidad fraccionada franco-alemana es objeto de una meditación extensa e intensa en E. Curtius, para resolver hacia 1947 en enraizamiento latino para la literatura - y cultura, e identidad- europea. España era el hueso duro de roer, mientras algunos alemanes, como L. Pfandl o K. Vossler, se volvían a ella para buscar allí el consuelo que no encontraban en Francia.

El continente, franco-alemán siempre, seguía aislado de Inglaterra por el Canal de la Mancha en tiempos de tormenta. Y George Orwell- un ex-alumno de Etonjunto a otros muchos, convertía todo esto en literatura propia y fascinante, de 1943 a 1949, de Animal Farm a 1984, itinerario salpicado además de un insobornable ejercicio de ensayismo no sólo crítico-literario. Inside the Whale, una implacable anatomía de la escena literaria de los veinte-treinta- Kipling, Miller, Eliot, Auden, tantos otros...- es de 1940; The Lion and the Unicorn, una no menos implacable vivisección- encausamiento y elogio- del perfil identitario inglés en el momento del challenge que suponía enfrentarse en solitario al asedio de una Europa totalitaria, también es del mismo 1940. Bernard Crick (nacido en 1929, el autor de In 
defence of Politics, un texto de 1962 que quizás no estaría mal leer en paralelo con The Revolt) afirma haber leído Animal Farm - historia de la deriva falsificada de una revolt - en el momento inmediato a su publicación, y no hay razón para considerar el caso excepcional, sobre todo si de gente de sensibilidad literaria se trata.

No parece que pudiera quedar esto en el extramuros de Eton. Literaturas inglesa y española periferizadas, literatura alemana y francesa- el objeto de estudio del joven Elliott- centrales y escindidas. Europa era esa unidad en la diversidad. El Elliott que en 1949 accede a Cambridge elige historia, y como Elliott mismo ha afirmado, «estaba volviendo a un temprano entusiasmo», el de los años previos a Eton y la fascinación por la popular serie The Romance of the Nation. A Stirring Pageant of the British Peoples throught the Ages. Pero se vuelve desde la literatura. Y ya no se vuelve al mismo lugar. Quizás el historiador que mucho más tarde puede desarrollar, en Europe divided (1969), un fascinante e insuperado ejercicio narrativo sobre el conjunto de la experiencia europea de la segunda mitad del XVI, parte de un concepto que tuvo su primera acuñación como literatura europea: se trata, afirma en julio de 1968, de poner de manifiesto «la compleja interconexión de los acontecimientos en el continente y el sentido que tenían los contemporáneos de que se hallaban implicados en un gran drama europeo». Pero por el momento, cuando John Elliott accede a un Cambridge que en 1949 es el escenario de los primeros episodios de lo que más tarde se reconocerá como linguistic turn, - la edición de textos de Filmer por Peter Laslett es de ese año- lo hace llevando consigo un personal literary turn de factura propia. Todo ello interesaba a la Modern History a la vez que a la historia del political thought. En el año en que Orwell publicaba 1984, el ambiente en Cambridge y la incipiente forma de mirar de Elliott entran en un rumbo de colisión que se revelará muy productivo.

Cambridge en 1949 podía ser muchas cosas. Pero era, entre otras, el lugar donde la presencia del professor — desde 1944- allí titular de la cátedra de Modern History se hizo bien visible con la publicación de tres libros simultáneamente: Christianity and History, primero; The Origins of Modern Science, luego; por último George III, Lord North and the People, 1779-1780. Eran los tres obra de Herbert Butterfield. No son sólo lectura posible. Son expresión de una atmósfera, articulación de unas condiciones de posibilidad para el estudiante que precisamente desde este 1949 se enfrentara a tres cursos de formal training en un syllabus de historia. Por el momento- sólo por el momento- podemos dejar de lado la voluminosa monografía acerca de un Rey, su statesman, y un pueblo revoltoso en su alrededor en tiempo de crisis de Empire. Podemos dejar de lado por el momento la discusión que el segundo libro - responsable, si no de la acuñación del concepto de «Revolución Científica», si de la conversión del concepto en paradigmaentablaba con otro, famoso y francés, La crise de la conscience européenne. Interesa sobre todo Christianity in History - conferencias radiofónicas, antes que libro impreso- porque entre sus epígrafes puede espigarse algo muy significativo: «The interpretation of Human drama», «The tragic element in human conflict». De hecho, todo estaba ya en su lección inaugural en la cátedra, de 1944, The Study of modern History: atendiendo al «system of necessity», a las «varying forms and 
degree of necessity», "the historian explains things putting them back into their relevant context", esto es, "the narrative itself assumes a different shape, when has been returned to its context and is seen in its proper bearings", pues es entonces cuando "over and over again, what had once been told as melodrama has had to be reconstructed- often assuming the form of tragedy". Más claro, en algún texto de 1949-1950 de los recopilados por Butterfield para componer su History and Human Relations, de 1951: "The central fact - the one that gives the new structure to the whole narrative - is a certain predicament, a certain situation that contains the elements of conflict irrespective of any special wickedness in any of the parties concerned»: es entonces cuando "The higher historiography moves away from melodrama and brings out the tragic element in human conflict».

¿Quién elige a quién, cuando tras tres años de respirar esta atmósfera, John Elliott endereza a Herbert Butterfield el asunto de una tesis sobre el statecraft de un ministro español que intenta, y no logra, evitar a su Rey una revolt en tiempo de crisis de Imperio? No es el tema, es la mirada, la atención hacia el componente dramático siempre susceptible de reconstruirse como tragedia, lo que se destila sobre un John Elliott mientras se familiariza con la historia económica y la historia constitucional (inglesas), con historia medieval e historia moderna (europeas), impartidas por Walter Ullmann o Steven Runciman, David Knowles o Jack Plumb, en sus tres años de undergraduate, 1949-1952. La atención a la historia mediada desde Eton por la literatura moderna europea y sus fisuras, ahora en sobreexposición ante un ejercicio fascinante de dramatización.

Por lo demás, también en el entorno de Butterfield, aunque no sólo, las formas de relato mítico se sometían a escrutinio crítico, cuando el trabajo sobre The norman Yoke en marcha por Christopher Hill hacía que Butterfield recomendara a uno de sus alumnos aventajados que se dedicara a la disección del mito antitético al del yugo normando, a saber, el de la Ancient Constitution. Años de 1948 a 1952. Con estos mimbres, al Elliott que le había fascinado en 1948 la lectura de Toynbee, y en 1949 la de Braudel, podía someter esa fascinación-e irritación- a un personal control, adaptación, atemperación y modificación. Habría «challenge», e historia "économique et social» en su escritura futura de la historia. Pero sin idolización obsesiva hacia ninguna de las dos cosas, y sí acercamiento atento a las ironías, y paradojas que suelen inscribirse en todo drama trágico, en su predicament. Tres cursos de aprendizaje formal de historia en una atmósfera habitada entre otros por Herbert Butterfield en estos términos no podían dejar de combinarse eficazmente con la sensibilidad propia de que ya era portador John Elliott, una sensibilidad para el componente imaginativo que Herbert Butterfield, aunque lejos de la condición de experto en historia española- quizá precisamente por eso- multiplicaría exponencialmente sugiriendo «intuición» como resorte último para la escritura. El autor del fascinante librito de 1940 sobre The Statecraft of 
Machiavelli, sugerente detección de formas de maquiavelismo en suelo monárquico- con Bolingbroke, para el caso- no sólo brindaba temas posibles para la investigación. Brindaba sobre todo una mirada compleja hacia la complejidad que Elliott se encargaría, ya por su cuenta, de agrandar y refinar.

Para empezar, interesándose también por la obra de Lewis Namier. Herbert Butterfield era, antes y a la vez que el autor de la lección inaugural de 1944 y de la triple consecución de 1949, el autor de dos piezas cruciales, en 1931 y 1944 de encausamiento y celebración de la tradición de escritura de la historia en Inglaterra. Era el autor de The Whig interpretation of History, de 1931 y de The Englishman and his History, de 1944. O por decirlo en expresión de un excelente conocedor y eficaz heredero también de estos textos, la mera presencia de Butterfield planteaba el problema de "cómo se debería relacionar el progresismo complaciente que Butterfield criticaba en The Whig Interpretation of History... con el tradicionalismo igualmente complaciente que tanto admiraba cuando escribió su citada obra de 1944 (The Englishman and his History)» (John Pocock). La peculiar respuesta del estudiante John Elliott consistió, a lo que parece, en una personal apropiación de la obra del historiador ruso-polaco, por origen Niemirowski, y por aclimatación inglesa Lewis Bernstein Namier, luego Sir Lewis Namier en 1952. Para esa fecha, Namier y sus discípulos habían convertido sus monografías de ruptura de 1929 y 1930- The structure of Politics at the accession of George III, y England in the Age of the American Revolution, respectivamente- en namierismo, esto es: atención, prosopografía mediante, al juego faccional y clientelar en sede parlamentaria y aledaños, y desatención al exhibicionismo ideal-constitucional encubridor de puros intereses. En monografías propias y trabajo colectivo de la segunda postguerra, como se sabe, desde Manchester se desarrollaría un episodio de enfrentamiento precisamente con la muy articulada posición que representaba Butterfield. Una cause célebre en la historia de la historiografía, muchas veces ya anatomizada. Por debajo del hielo de lo que Butterfield identificaba como whig interpretation y reconstruía como historia de un consenso nation wide que había permitido a la nación encarar con éxito la prueba de 1940, la persuasión namierita reconstruía un siglo XVIII desde la prevalencia de las interconexiones faccionales de la oligarquía. Lecciones a la hora de caminar hacia la graduación, hacia 1952.

Y un signo, también de ese momento preciso de 1952, puede traerse a colación, precisamente para ilustrar el engranaje de resiliencia y cambio que afectaba al filo rosso de todo esto, la historia constitucional de impronta "Stubbsiana»: en ese año en que Elliott culminaba su graduación- un itinerario en el que la formación en historia constitucional hacía de estructura portante de la historia generalse publicaba la colección de textos, con destino a la enseñanza universitaria, de W. C. Costin y J. Steven Watson, The Law and Working of the Constitution. Documents 1660-1914. Una autoridad en la materia, Richard Pares, saludaba en reseña de Past \& Present, de noviembre de 1952, la novedad del asunto: estaba en el "working" del complejo constitucional, que inflexionaba significativamente sobre el solitario «Law of the Constitution» de, pongamos, un A. V. Dicey. Las venerables colecciones documentales que eran trasiego imprescindible del estudiantado de 
oxbridge, si de historia tout court se trataba, de Stubbs a Keir pasando por Gardiner y Tanner, pudieron educar la mirada de quien se disponía a enfrentarse con una textualidad sólo hasta cierto punto otra.

Una combinación inteligente de atención namierita y de imaginación à la Butterfield, siempre como irradiación de fondo la aludida resiliencia y transformación, lo uno con lo otro, del paradigma whig, llevó a Elliott a proponer al segundo, como supervisor de su trabajo de investigador de posgrado, el proyecto de un tema de investigación para una futura tesis: Statecraft, el estadista, su rey, el Imperio en su momento de crisis. Son avatares que pueden seguirse en History in the Making, con algo más de pormenor que hasta ahora. Interesa subrayar aquí que la forma de mirar de Eliott ya es de acuñación propia, producto de una combinatoria altamente personal de las corrientes atmosféricas que debieron hacer fascinante el clima de Cambridge, intermitentemente aireado por visitas a España. Una personalísima forma de «tormenta perfecta», por lo demás tranquila, se estaba generando en Elliot cuando recién graduado (1952) emprende el camino de la investigación, en suelo inglés un año (1952/1953), en suelo español (Simancas y Barcelona), otro inmediatamente (1953/1954). Posiblemente esa forma de mirar le permite detectar en un documento de 1624 (que se presentaba hecho jirones en Marañón, en Martín Hume, en Cánovas, pronto recuperado íntegro en la British Library en ese año inglés de postgraduación investigadora), toda la gramática del asunto constitucional español en su momento crítico. Puede que nunca un itinerario de investigación tan sostenido, eficaz y masivo haya dependido tanto de un solo documento por lo demás único: de la lectura con otra mirada de un mismo y asendereado documento. Donde los demás leían centralización y maquiavelismo, Elliott, que sabe del statecraft de Maquiavelo y de las ironías inscritas en ciertas tragedias, ve predicament, dilema, paradoja e ironía. Los ingredientes con que dejar de contar el drama como melodrama y pasar a inscribirlo como, quizás, tragedia. Se viaja a España-como Tocqueville a América - ya con el país de destino en el bolsillo.

Para lo cual había ayudas que, si falta hiciera, ayudaban aún más a aguzar la mirada. La vieja guía de viaje para hispanistas que fuera en tiempos el Spain. Companion to Spanish Studies de Edgar Allison Peers- experto en romanticismo español, autor en 1936 de un Spanish Tragedy, 1930-1936, Dictatorship, , Republic, Chaos, Rebellion, War, y en 1943 de un Spain in eclipse, 1937-1943. A sequel to the Spanish Tragedy, con un Catalonia infelix de por medio en 1940- que venía experimentando adaptaciones y reelaboraciones desde su primera edición en 1929, con los capítulos de historia a cargo del mismo E. A. Peers, tenía a la altura de 1949 un sorprendente sustituto, también como guía de viaje, manual casi obligado del viajero en tierras españolas. A saber, la versión, generosamente anotada, al inglés, de Los Españoles en la historia de Ramón Menéndez Pidal, texto 
inaugural de 1947 convertido por Walter Starkie en 1949 en The Spaniards and their History. Casi, por el título, para España, el libro de Butterfield de 1944. Y sin embargo, nada más distante, aunque se planteara como celebración de una tradición, del libro de Butterfield. Si se va derechamente al capítulo II, «Idealism», se encontrará al Conde-Duque en compañía de Quevedo, y de Fernández Navarrete, en tiempos de decline, apostillándose en nota: «Conde Duque de Olivares, famous minister of Philip IV from 1621 to 1643, was pictured several times by Velázquez. The epistle of Quevedo was writen in 1624». Era lo que daba de sí, no un hispanismo, sino la mismísima historiografía española en expresión de su más caracterizado representante. Pero había mejores guías.

Con Alexander A. Parker, esa guía mejor estaba servida desde la filología. Parker era el autor, en 1943, the The Allegorical Drama of Calderón, un antes y un después en los estudios calderonianos, por tanto de la fibra más sensible, e inexportable, del tejido literario que daba expresión a la cultura española del Seiscientos. Un estudioso que sabía elevar la puntería de esa preocupación disciplinar hacia espacios de crítica no sólo literaria. En mayo de 1953 era el autor de un breve e intenso artículo, publicado en el Cambridge Historical Journal, «The roots of the Spanish Dilemma», donde de Masson de Morvilliers a Unamuno, Castro y compañía, se encaraba con una cultura cuya preocupación «with the problema of national "decadence", which had been a constant feature of spanish life for over a century, now becomes an obsession which often assumes morbid forms", y lo que era peor, traducía esa obsesión en «unintelligent forms then taken by the historical controversy concerning the causes and origins of Spanish "decadence"». Toda una incitación, todo un programa, para quien ya compartía un lenguaje: «lts real tragedy is completely hidden by the facile división into "Fascist" and "Comunist" and the quick dismissal of one or the other", una tragedia «also tinged with irony". La conferencia madrileña de Parker en 1951, Valor actual del humanismo español, se publicaría a principios de 1952, y venía a ser una sostenida exploración, en su breve puñado de páginas, de las paradojas que atraviesan el clima literario de Cervantes a Calderón, que constituyen ese clima. Probablemente la monografía calderoniana de 1943 no alcanzó por entonces al Elliott que progresaba en Eton en materia de literatura franco-alemana. Lo que representan los otros textos forma parte de la atención necesaria para quien desde 1952 se preparaba para un viaje de investigación en España, y emprendía ese viaje en 1953.

En 1952 y 1953, y tras siete años de preparación, se publicaron en Barcelona los dos primeros volúmenes de la Historia de España de Ferran Soldevila. Seguirían otros, sin pausa, hasta completar los ocho volúmenes en 1959, alcanzando 1898 en su relato. Interesan ahora los dos primeros porque su arquitectura escapaba elegantemente a la trampa historiográfica que denunciara Alexander Parker. El autor, en 1934/1935, de una Història de Catalunya que había sido pieza crucial en la institucionalización de una historiografía catalana en torno a los Estudis Universitaris, se aplicaba ahora a la elaboración de un edificio mayor cuya estructura y propósito ya se vislumbraba perfectamente en esa primera entrega doble: el argumento era la contención de un esfuerzo hegemónico castellano por 
un esfuerzo peninsular equilibrador catalán, y la parálisis de esto último al monopolizarse desde Castilla un completamiento de la recuperación territorial, y paralizarse incluso esto mismo por el despliegue peninsular de los Trastámara. Todo, por lo demás, con explícitas referencias a la interacción de esos elementos como interacción de un centro con varias periferias y además con una exquisita atención a la interacción de los elementos jurídicos con los más materiales. Aunque quizás eso no era Vicens, decididamente ya no era, para nada, Rovira y Virgili. Nada de las «formas mórbidas» que la obsesión nacional promovía en la historiografía española del momento. Añádase que, en enero de 1953, Vicens publicaba su Aproximación a la Historia de España. Era un texto, para empezar, fuertemente imbricado en una idea fuerte de universidad, y sin embargo con vocación de no recluirse en ningún enclaustramiento universitario. El texto de Soldevila parecía condenado a moverse, precisamente, fuera del ámbito universitario, como su autor, definitivamente bloqueada su reincorporación a escalafón docente alguno. Pero muy cerca de Vicens. La muy conocida imagen fotográfica de 1957, en Cerdeña, con un pujante Vicens hablando en pie, traje de corte impecable, agazapados al fondo sus discípulos Giralt y Nadal, y un envejecido Soldevila sentado y mirando hacia Vicens, arrebujado en un pesado abrigo, quizás podría ser sometida a un hipotético efecto moviola y, trasladada a 1952, quizás la figura de Soldevila se agrandaría en estatura. Su Historia de España la tiene, desde luego, y sirve para articular con mayor complejidad el ambiente catalán en el que iba a desembarcar, al poco, John Elliott.

Para cuando lo haga, Elliott podía ser portador de su particular forma de atención hacia la interacción de centro y periferia. En la London School of Economics, en la inmediata postguerra, entre 1945 y 1950, impartía lecciones de sociología Edward Shils, para hacerlo luego en Cambridge desde 1960. Lo fundamental de esas lecciones se publicaría en el homenaje a Karl Polanyi en 1961, con el título "Center and Periphery». Adaptando a su ya más que conformada forma de mirar esas incitaciones, John Elliott podía permitirse, con ocasión de su primera visita de investigación a España, una notable independencia de criterio respecto al tándem Soldevila-Vicens, una vez que la «revuelta catalana» había sustituído a «Olivares» como centro de la investigación. La rápidez de reflejos mostrada en Simancas en unas semanas críticas de 1953 por Elliott tenía fuertes apoyaturas propias. La tragedia de Olivares, prolongada más allá de 1643 en la pérdida de sus papeles personales a finales del XVIII, no necesariamente tenía que ser una tragedia personal para el joven investigador británico. Había ya construido un propio «mental world» que le permitió sobreponerse productivamente a la catástrofe, y convertir precisamente ésta, y es ironía, en el origen de la investigación que culminaría como The Revolt. Luego vendría, de vuelta a Inglaterra, primavera de 1954, la generación de la dissertation, más de mil páginas, fábrica propia de la que derivaría, a una velocidad espectacular, la escritura posterior, la publicada en 1955. Hemos cerrado el círculo, y detectado, de Eton a Cambridge, la formación de una personalísima mirada que sin embargo retoma holgada los pliegues del contexto menos personal. Personal e impersonal. The Revolt es el resultado de eso. Repa- 
semos el rastro de esa forma de atención en los textos que dan visibilidad incipiente a Elliott desde 1955.

Un artículo primero, nada primerizo, en Estudios de Historia Moderna se abre con líneas donde se transparenta Butterfield a cada paso: el asunto inicial es el de la mitología de la revolución obstruyendo su historiografía. La mecánica interna al Gran Memorial está ya, inmediatamente, desmontada y vuelta a montar, y se saben sacar las consecuencias narrativas de ese (des)montaje, pero eso se hace deconstruyendo romanticismo, folklore, nostalgia y mito en un choque tan frontal como educado con una historiografía, y una política de esa historiografía, a la que conviene recordar explícitamente que necesita un Butterfield. Es un recordatorio que ya no tiene sentido en el texto inmediato, ya para consumo británico, el de Cambridge Historical Journal del mismo año de 1955. Aquí el explícito ejercicio à la Butterfield no necesita ser reiterado en un texto para un auditorio británico al que no tiene que contar qué es la whig interpretation, y se pasa entonces más derechamente a una reconstrucción namierita de los intereses que vertebraban a la élite provincial catalana, haciendo instrumental el vocabulario constitucional y la retórica pactista de expresión de esos intereses: cargos, nombramientos, oficios, inmediatez al ejercicio de favor real. Pero es un namierismo bien temperado: no se nos propina pura prosopografía de los revoltosos catalanes - ni castellanos- y sus mayores en tiempo de los felipes. El namierismo de Elliott deja juego a lo constitucional- a la vigencia de sus formas, bien que sometidas a deformación, a torsión, a invalidación incluso: constituyen a la «Monarquía»- en un ejercicio de matización jurídica que ya querrían para sí muchos historiadores del derecho. El espíritu de Maitland- otro ex-alumno de Eton- parece planear sobre todo esto. También el de Sir Ronald Syme, en tránsito desde la detección prosopográfica de The Roman Revolution a la encuesta comparada de las élites provinciales en la colonización romana y español-americana. Un namierismo, en suma de rostro humano, que quizás podría resultar ejemplar incluso para el namierismo feroz y reduccionista que practicaban desde Manchester los sucesores de Sir Lewis.

Que la guerra imprimía un aspecto trágico a todo esto, es el asunto desde el que Elliott interviene en la tormenta de ideas abierta por el seminal artículo de Hobsbawm. Está en el ambiente, para algunos, la centralidad de esa experiencia: por ejemplo, para Michael Oakeshott, que hace de la guerra, en sus lecciones de la London School of Economics desde 1951, el motor impulsor de la forma de asociación reconocible como Estado moderno. Y la estructura dramático-trágica de la historia de España cuando pasa del escenario de vísperas de Vervins al de Westfalia, de la percepción de Cellórigo a la de Saavedra Fajardo, le hace a Elliott abrir su contribución a la New Cambridge Modern History con una escenificación dramática- 1598 - que resulta imposible no citar: "»Cuando nos deje (Felipe II) nos encontraremos en otro escenario en el que todos los personajes del drama 
serán diferentes", decía un noble español un año antes de su muerte. Cuando esto sucedió, no sólo había cambiado el «reparto» sino que el propio drama se convirtió en tragedia". Esta forma de abordaje del asunto se compartía y anticipaba por otra entrega para la misma serie, volumen anterior (1958, compuesto en 1953/1956), por un Helmut G. Koenigsberger que asumía el análisis del Imperio de Carlos de Habsburgo desde registros explícitamente trágicos: «lt seems to me that there was an element of tragedy in the transformation and decline of Charles V's imperial ideal. This transformation and decline set in as soon as the ideal was formulated; it was inherent in the characters of the principal actors and in the political circumstances of the age, but it took four generations to play itself out. The stress on the tragic element of this story is not, I think, the result of romanticism of my part but, I hope, of a recognition of some basic elements of the human condition that the history of the Habsburg predominance exemplifies». Que el carácter compuesto de ese imperio, más allá de la unicidad que le prestaba la persona de su gobernante, fuera luego el centro de la narrativa, era algo que venía servido como componente estructural de ese drama. Por el momento, era síntoma quizás de qué atmósfera podía compartirse en las cercanías de Herbert Butterfield. El Festschrift que se le dedicara en 1970 por sus discípulos y afines estaría coordinado por John Elliott y Helmut Koenigsberger.

En cualquier caso, era esa arquitectura regional endiabladamente encanallada, de encanallamiento amplificado cuando el «imperio» era el de la «España» de los felipes, lo que ya sabemos que permitió ahora entrar en el examen de la decadencia desde ángulos desatendidos por Earl J. Hamilton e incluso por P. Vilar, en la contribución para Past \& Present publicada en 1961. Tras haber situado la revuelta catalana en un horizonte «general», enmendando así la plana al Merriman de 1938, se retomaba el Merriman de 1918, quizás combinándolo con el Soldevila de la Historia de España, para dar complejidad regional a la «decadencia». El tiempo «del Quijote» se le volvía a Elliott el tiempo de un castellanismo exacerbado que obligaba a Olivares a jugar con las cartas marcadas (I. A. A Thompson ha sabido retomar estupendamente algunos aspectos de esta posición) desde 1621. A jugar y a perder ante la intransigencia castellana, reduplicada en el espejo curvo de la intransigencia catalana. Era la tragedia, la que se dice «tragedia de España» en la última línea de The Revolt.

\section{(vii)}

The Revolt, como Imperial Spain, trae en forma ampliada todo lo anterior: en definitiva, un Elliott que sabe incorporar-componer-en su imaginación historiográfica lo mejor de Namier con lo más operativo de Butterfield: que sabe no engolfarse en la prosopografía y se atiene a la omnipresencia, si bien esclerotizada, de un «constitutional pattern» cuyo working se mostrará incapaz de ser ya vehículo para el monopolio castellano del festín de oficios y patronazgo cuando el desmantelamiento material se hacía irreversible. La namierización, merece la pena repe- 
tirlo, no arroja por la borda lo constitucional que ejemplificara un Tanner, sino que lo refina, lo redimensiona y lo convierte en fuente de paradojas, dilemas, ironías, desde posiciones de predicament que el historiador no intenta resolver, sino enfrentar de manera comprensiva.

Understanding es en History in the Making la última palabra. Misunderstanding es la historia que reconstruye para castellanos y catalanes, imposibles españoles, The Revolt of the Catalans. Es el relato que se trama, ahora afirmado con un respaldo de información y una expresión literaria que alejan la tentativa de cualquier «España como problema» o «España sin problema». Lo mejor de $\mathrm{Na}$ mier, lo más operativo de Butterfield, y algún plus: a este respecto, la mención de A. A. Parker en los agradecimientos de Imperial Spain vale, además de indicación de un filón hermenéutico, por toda una declaración de método. No es improvisada y remite, más allá de ese concreto estudioso de las letras áureas hispánicas, a un estrato profundo de la forma de mirar de John Elliott. Hay una profunda congruencia en que luego esa mirada sepa interesarse por las formas en que se construye un Palacio para un Rey, o persiga la presencia de un «Momento nebrisense» en el universo lingüístico de Felipe IV, acompañando la lengua al Imperio. No es ni moda ni improvisación.

Hay continuidad, y curiosidad atenta, desde las posiciones de fondo. Merece la pena atender algún recurso expositivo del reciente History in the Making. No es posible que alguien como Elliott, tan atento a las cuestiones de estilo a la hora de la economía expositiva, deslice por casualidad, o por cualquier otra cosa peor, dos fragmentos de poesía inglesa en el arranque y el cierre del libro- uno de ellos, de poesía dramática. Exactamente primera y última citas. El libro se abre con una cita de R. Kipling, y se cierra con otra de T. S. Eliot. La primera remite a las muchas formas posibles que reviste el contar historias, secantes y tangentes con la historiografía muchas de las veces. La segunda, tres versos de las stanzas iniciales de The Rock, le sirve para dar expresión al mensaje del texto que quiere que retengamos en el momento de abandonar la lectura. Eliot — sin doble II, sin doble tt- habla de cómo se pierde la sabiduría al transmutarse en conocimiento, y cómo éste se nos escurre entre los dedos al convertirse en información. Unos versos corales de 1934. Y resulta que es la misma, exactamente la misma tríada- "wisdom», «knowledge», «information»- desde la que hace partir su meditación Michael Oakeshott en Experience and its modes. En 1933. La composición de lugar y el tiempo son literalmente coincidentes. Herbert Butterfield quizás sonreiría, y remitiría a su texto de 1949: de la Providencia en la Historia... (y Oakeshott hizo una primera recopilación de artículos dispersos, Rationalism in Politics, en 1962, otro libro que, como el de Crick ya mencionado, también podría no descabelladamente ayudar a triangular la posición de The Revolt; ¿providencial, también?). Las 624 páginas de The Revolt son, en la delgada línea roja que da continuidad a este relato, de 1930 a 2012, 83 años, el eslabón crucial. Cualquier otro nos hubiera obsequiado una muy especulativa dilucidación de la epistemología del saber histórico. A Elliott le basta con una cita de Eliot.

No es el montante de información, que puede ser espectacular, lo que al acomo- 
darse en la arquitectura del texto debe hacer que merezca la pena su visita. No es el nivel de conocimiento que transmite lo que puede hacer que nos engolfemos en su lectura. Es la sabiduría de fondo, con sus incitaciones - Oakeshott diría intimationsque podemos hacer nuestras, lo que conserva fresco el relato, al medio siglo de su escritura. Esa sensibilidad de fondo se adquiere como literatura, a lo que parece, y no parece tan alejada del taller del historiador. Es el Etonian moment. Aquí se comenta su acuñación elliottiana. Y siendo consciente de las muchas máscaras que se pueden lucir en ese taller, sabe que una de ellas es la de actor en el drama de la construcción de la identidad nacional. Conviene resistirse. Pero no dar por ninguno el trance — predicament, intraducible - huyendo hacia adelante e inventando - descubriendo- Mediterráneos. También es esto lección nuclear de History in the Making, y todo The Revolt una nota al pie de esa aseveración. O también a la viceversa.

Estamos, con estos textos, en un baile de máscaras —una forma de dramatización, al fin y al cabo. Antes incluso de la cita de Kipling, en la primera línea de History in the Making, Elliott ya nos ha convertido su libro en un estupendo espectáculo: «Este libro es a la vez personal e impersonal». No puede decirse con más economía de palabras - ni con un más transparente guiño eliotano- lo que constituye La paradoxe sur le comèdien...

Y no es la menor de las paradojas que todo esto, en The Revolt, se aplique a España sin tentación de hispanismo. «Fortunate the historian whose chosen country has so much to offer! ", así acaba de resumir en un trazo rápido Elliott su relación con España, y con la historia de España. Y elegantemente su último comentarista (Keith Thomas) puede apostillar: "fortunate the country that has such a historian", lo cual, en su pizca de ambigüedad, puede referirse tanto a Gran Bretaña como a España. Y cabe añadirse, ante la reposición del clásico, The Revolt, en un escenario ciertamente movido, cincuenta años después, con declaración catalana de soberanía de por medio: afortunados los espectadores cuando en medio del drama un actor intruso irrumpe en el escenario, y domina la escena en curso con un perfecto control del papel que representa - incorporado sobresalientemente su personal actor's studio; cuando muestra capacidad para la improvisación sobre las tablas-catástrofe simanquina en torno a los papeles, perdidos para siempre, de Olivares - y para la interacción con ese público - vale decir, el total de la bibliografía de John Elliott. Cuando resulta apoyatura generosa para el resto del reparto, bisoño o no tanto. En fin, cuando despliega carácter. Paradoja penúltima: puesto que «that is not entertainment», que continúe, pues, el espectáculo.

NB.: Las páginas anteriores, redactadas en mayo de 2013, se deben a iniciativa, magistral y amical, irresistible por tanto, de Pablo Fernández Albaladejo, que quiso regalar a su autor la aventura de la composición conjunta de un «Epílogo» destinado a la reimpresión por la Editorial Akal, de la versión castellana de The 
Revolt of the Catalans. Es el primer reconocimiento que debe avanzarse. Cuestiones de disponibilidad de espacio obligaron, a la hora de combinarse la composición de páginas de uno y otro, a una cierta reducción de contenido. El texto conjunto, «John Elliott. El intruso a escena», donde se combinan esas páginas y las de Pablo Fernández Albaladejo, se publicará por Akal a principios de 2014. En su «nota» bibliográfica final se encuentran las referencias exactas a textos de Elliott citados en estas líneas, y no ha parecido pertinente reproducirlas ahora. De la amabilidad y profesionalidad, en Akal, de Tomás Rodríguez, editor del texto, también conviene dar aquí noticia agradecida.

Se debe también a Pablo Fernández Albaladejo la insistencia respecto a la publicación del texto completo original, y aquí es donde el agradecimiento debe hacerse extensivo - y es extensión que se hace naturalmente- a José María Iñurritegui, que generosamente abrió las páginas de Espacio, Tiempo y Forma, y brindó el privilegio de inaugurar sección de historiografía, al texto completo. Este se publica como se redactó, con la adición de mínimos retoques de detalle y disposición, y del título y la cita en exergo con las que se quiere indicar el sentido del ensayo. La dedicatoria, ahora, reconoce una deuda larga de tiempo con Saúl Martínez, que me convirtió en aprendiz de taller fingiendo ayudarme a dar mis clases en la UAM.Y, al final pero no en último lugar, es grato al autor reiterar el reconocimiento que ya se hizo en el citado «Epílogo» hacia Xavier Gil Pujol, bastante más que animador, actor imprescindible también de esta aventura.

El Escorial, julio-septiembre de 2013. 